Yellow rain

\title{
Contradictory accounts gathered in Laos
}

\section{Washington}

Two Americans who were allowed to conduct on-the-scene investigations of reported "yellow rain" attacks against Hmong villagers in Laos are about to publish findings that raise considerable doubt about US State Department allegations of the use of chemical weapons in the region.

In January and February this year, Jacqui Chagnon and Roger Rumpf visited several areas that have figured in US reports of yellow rain attacks. They are fluent in Laotian, having worked as field directors for the American Friends Service Committee in Laos from 1978 to 1981. During that time they were in a party of international aid representatives who toured the Phu Bia mountain area, a centre of Hmong resistance, at the same time (March 1979) that chemical attacks were going on there according to State Department charges.

Their interviews with Hmong villagers and Lao government officials this year appear to contradict both in detail and in general impression, the US charges that the Laotian government, with Soviet support, is waging genocidal war against the Hmong and is using chemical weapons to do so.

The US charges are based on interviews with refugees in Thailand, on intelligence reports and on chemical analyses of blood samples which show the presence of trichothecene mycotoxins, the fungal toxins that the United States says are being used as a chemical weapon. However, neither US officials nor a United Nations scientific team have been allowed inside Laos to investigate the reports.

Chagnon and Rumpf were permitted to travel through the countryside and conduct interviews, often in the presence of government officials. The most striking of their findings, which are soon to be published in a specialist journal on South-East Asia*, is the mixture of story-telling, rumour, myth and contradiction that worked its way into accounts of yellow rain told to them by Hmong villagers; striking, too, is the fact that many of the accounts of yellow rain or droplets and associated deaths and illness came from Laotian government officials.

A typical instance occurred in Ban Done, a Hmong village that has been cited by many Hmong refugees in Thailand as the site of chemical attacks. In Ban Done, Chagnon and Rumpf interviewed a government official, Xua Chang Her, a Hmong who related how he saw yellow "fog or smoke"' killing people, buffalo and rice in several villages in 1982. Similar stories came from villagers who had fought with Vang Pao; none, however, connected the phenomenon with aircraft flying over or even with warfare. Several contradictory accounts (some of the contradictions appearing in the story of a single teller), dated the poisoning to December 1981 or September 1982.

In another village, yellow rain stories again brought up by a local Hmong leader who sided with the government - were vigorously affirmed by everyone except the local medic, who said the ills the villagers ascribed to poisoning were in fact the result of cerebral malaria, a prevalent problem in the region. Chagnon and Rumpf report that none of two dozen foreign relief workers they spoke to who had travelled throughout the Hmong areas had seen any evidence of "yellow poisons".

Although they avoid drawing any firm conclusions about the use of chemical weapons or the nature of yellow rain, Chagnon and Rumpf suggest that more cross-checking within Laos of refugee stories and intelligence reports is necessary. They say that they were told by a viceminister of the Laos foreign ministry that Laos would now consider allowing a private, impartial team of scientists into the country to investigate the yellow rain charges, and that a similar comment was made by the prime minister to a prominent European diplomat. The government apparently continues to oppose any official delegation, even from the United Nations, and the problem has become one of organizing a private delegation and raising support.Chagnon estimates the cost to be at least $\$ 50,000-\$ 60,000$. The European diplomat who received the prime minister's assurances that such a delegation would be welcome reportedly tried to assemble a group of scientists in Europe and the United States, but has since been posted outside South-East Asia.

Stephen Budiansky

*Southeası Asia Chronicle; single copies available from Southeast Asia Resource Cenıre, 198 Broadway, Suite 302, New York, NY 10038; \$2.5.

\section{Computers}

\section{NSF pressed on supercomputers}

\section{Washington}

TEN supercomputer centres should be established in the next three years to improve US computational facilities for academic research, according to a draft report of a working group of the National Science Foundation (NSF).

In justification of the $\$ 200$ million it wants NSF to spend on the centres, the group says that "Important science is not being done in this country due to lack of access to adequate supercomputer capacity." The report adds: "Even these investments would not provide computing facilities for academic researchers comparable to those at a typical national or industrial research laboratory."

The group reports several trends in the 1970 s that led to the present neglect of large computing capabilities at universities. NSF itself stopped supporting campus computer centres in 1972; this support had allowed a number of universities to obtain the "supercomputers" of the period IBM 370 s and CDC 7600s. Meanwhile, individual departments and groups began acquiring their own mini and microcomputers, a move spurred on by the refusal of most federal funding agencies to support the full cost of purchased computer time in research grants. And, the report notes, many campus computer centres fell into "disrepute" among scientific users because they gave priority to small jobs and administrative and educational tasks.

According to the report, existing supercomputer facilities in the United States are either designed around a single discipline (such as the CRAY-1 parallelprocessor computers at the National Center for Atmospheric Research and the Department of Energy's Magnetic Fusion Energy Computer Center) or prohibitively expensive (typical charges running at $\$ 1,000-2,000$ per hour) or not configured (in hardware or software) for research uses. One American astrophysicist is said to have had to establish a collaboration with scientists in West Germany in order to gain access to an appropriately configured supercomputer.

Some critics of the NSF group's gung-ho attitude towards supercomputers complain that the supercomputer is a solution looking for a problem. However, after the NSF group convened a workshop in May to solicit suggestions for possible uses of supercomputers, the group was able to make a convincing case for such machines for several applications, including:

- quantum mechanical calculations of reactions of complex molecules;

- modelling of the formation of stars;

- modelling dynamic magnetic systems;

- fine-resolution modelling of the atmosphere and oceans.

The working group's report also recommends vastly increased support for the purchase of mini and microcomputers by individual groups and departments $\$ 240$ million over three years, up from the currently planned $\$ 170$ million - with special emphasis on engineering, physics, atmospheric research and computer science.

Stephen Budiansky 